\title{
Commissioning Test of ATLAS End-Cap Toroidal Magnets
}

\author{
Alexey Dudarev, H. H. J. ten Kate, J. Buskop, A. Foussat, P. Benoit, M. Jeckel, A. Olyunin, N. Kopeykin, \\ V. Stepanov, L. Deront, G. Olesen, X. Pons, S. Ravat, E. Sbrissa, K. Barth, J. Bremer, N. Delruelle, \\ J. Metselaar, R. Pengo, O. Pirotte, D. E. Baynham, F. S. Carr, and E. Holtom
}

\begin{abstract}
The system of superconducting toroids in the ATLAS experiment at CERN consists of three magnets. The Barrel Toroid was assembled and successfully tested in 2006 . Next, two End-Cap Toroids have been tested on surface at $77 \mathrm{~K}$ and installed in the cavern, 100-m underground. The End Cap Toroids are based on Al stabilized $\mathrm{Nb}-\mathrm{Ti} / \mathrm{Cu}$ Rutherford cables, arranged in double pancake coils and conduction cooled at $4.6 \mathrm{~K}$. The nominal current is $20.5 \mathrm{kA}$ at $4.1 \mathrm{~T}$ peak field in the windings and the stored energy is $250 \mathrm{MJ}$ per toroid. Prior to final testing of the entire ATLAS Toroidal system, each End Cap Toroid passed a commissioning test up to $21 \mathrm{kA}$ to guarantee a reliable performance in the final assembly. In this paper the test results are described. It includes the stages of test preparation, isolation vacuum pumping and leak testing, cooling down, step-by-step charging to full current, training quenches and quench recovery. By fast discharges the quench detection and protection system was checked to demonstrate a safe energy distribution within the magnet after a quench or a triggered fast dump.
\end{abstract}

Index Terms-Particle detector, superconducting magnet, toroid.

\section{INTRODUCTION}

$\mathbf{T}$ HE ATLAS muon spectrometer is based on the magnetic field of a superconducting toroid magnet system [1], [2] consisting of a Barrel Toroid (BT) and two End Cap Toroids (ECTA and ECTB). The main features of the End Cap Toroid (see Fig. 1), design and manufacture have been described elsewhere [3], [4]. Each ECT consists of a cold mass, eight superconducting coil modules and eight keystone boxes, mounted in a large castellated cryostat. The cold mass is indirectly cooled by pumped circulation of two phase helium. Prior to final testing of the entire ATLAS Toroidal system, each End Cap Toroid was tested up to $21 \mathrm{kA}$ to guarantee a reliable performance. The con-

Manuscript received August 21, 2008. First published June 23, 2009; current version published July 15,2009 . This project was funded by the ATLAS Collaboration, presently about 1900 scientific authors from 164 institutes in 35 countries and supported in part by CERN.

A. Dudarev, H. H. J. ten Kate, A. Foussat, P. Benoit, M. Jeckel, A. Olyunin, N. Kopeykin, V. Stepanov, L. Deront, G. Olesen, X. Pons, S. Ravat, E. Sbrissa, K. Barth, J. Bremer, N. Delruelle, J. Metselaar, R. Pengo, and O. Pirotte are with the European Center for Nuclear Research-CERN 1211, Geneva CH, Switzerland (e-mail: Alexey.Dudarev@cern.ch).

J. Buskop is with the European Center for Nuclear Research-CERN 1211, Geneva CH, Switzerland. He is also with NIKHEF, 1009 DB Amsterdam, The Netherlands (e-mail: Alexey.Dudarev@cern.ch).

D. E. Baynham, F. S. Carr, and E. Holtom are with the STFC, Rutherford Appleton Laboratory, Didcot, Oxon, U.K.

Color versions of one or more of the figures in this paper are available online at http://ieeexplore.ieee.org.

Digital Object Identifier 10.1109/TASC.2009.2019223

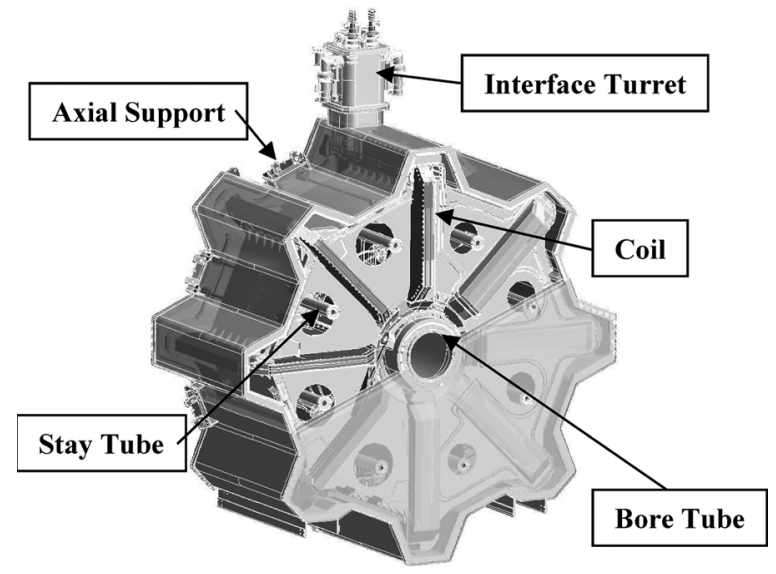

Fig. 1. CAD model view of an ECT. The vacuum vessel is shown with the eight coils separated by the keystone boxes. The bore stay tubes help to transfer the vacuum load between the endplates.

figuration used for the commissioning test was the final one and this helped to cross check all services at the same time.

\section{INSTALLATION}

The installation started with the lowering of ECTs (Fig. 1) into the ATLAS underground cavern, this was done in June and July 2007. The installation in the cavern entailed the connection of the cryogenics, the vacuum system, the power connection for the magnet as well as the instrumentation. The interface turret is shown in Fig. 2. A requirement from the ATLAS detector is that all services are connected at the top of the detector. For this a tower support structure for the services was installed. The tower structure is about $6 \mathrm{~m}$ in height and the services were pre-assembled inside the structure. Another requirement from the ATLAS detector is that the services connections are flexible to allow the magnet to be retracted $(\sim 6 \mathrm{~m})$ from the experiment and to be moved in a parking position (sideways $\sim 10 \mathrm{~m}$ ) while maintaining the magnet cold. To this end the services with the exception of the power connection of the magnet go via a chain. One side of the chain is connected to the support structure for the services and the other side fixed on top of the detector. The operation of moving the ECTs was tested and confirmed. The operation consists of sliding the ECT on its air-pads onto a support truck, retracted position, after which the support truck with the ECT is moved on air-pads to the parking position (Fig. 3). All the time the ECTs were maintained cold.

From the parking position the ECTs were put in their operation position. Given the fact that the ECTs are installed inside 


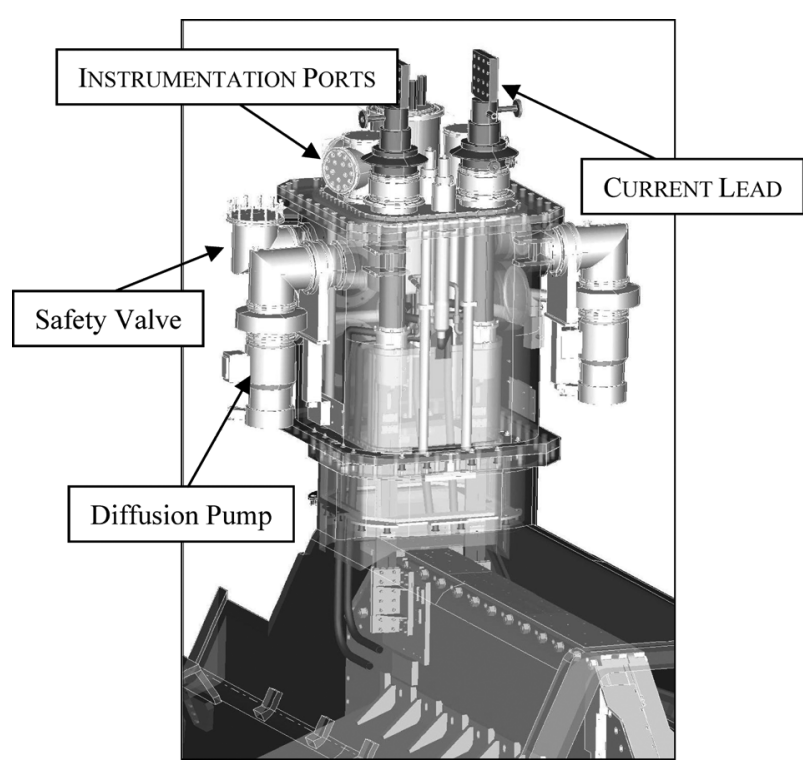

Fig. 2. All services are connected through the turret vessel to allow maintenance. Visible are the current leads and, behind them, the instrumentation ports and the cryogenic connections. The 90-degree elbows are the diffusion pumps. At the bottom of the current leads an additional support allows for the force caused by the Barrel Toroid to be taken.

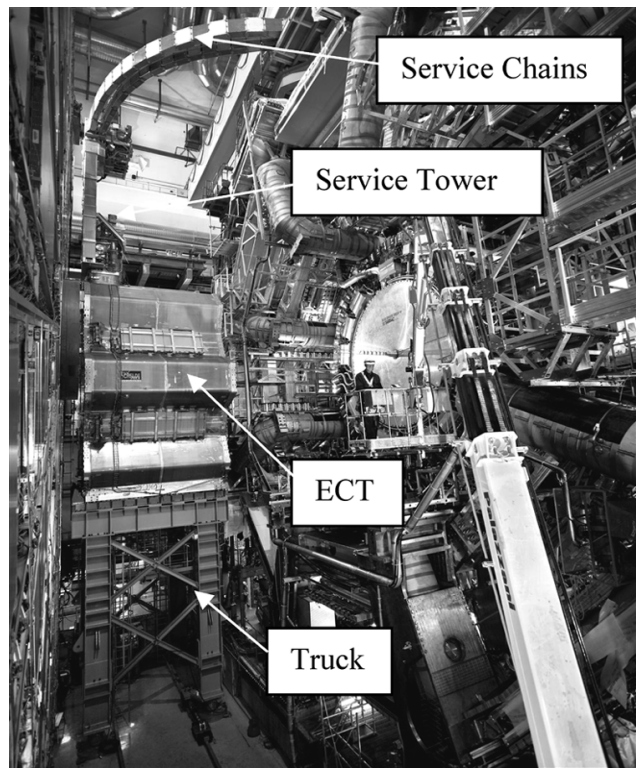

Fig. 3. ECT in parking position. To allow for detector maintenance, the ECT can be slid back onto the truck. The ECT moves on air-pads. For further access the truck with the ECT can be moved into a parking position with whole system moving on a second set of air-pads. Both magnets are kept cold as all required services go via a specially designed chain. A single chain with services is about $18 \mathrm{~m}$ in length and $2 \mathrm{t}$ in weight. Only the power bus bars are disconnected.

the ATLAS Barrel Toroid, the system must be accurately aligned to avoid undue forces on either magnet. Based on information from the assembly of the cold masses, the ECTs where positioned within $5 \mathrm{~mm}$ of the foreseen position. The undue forces can occur when the positional offsets are bigger than $10 \mathrm{~mm}$.

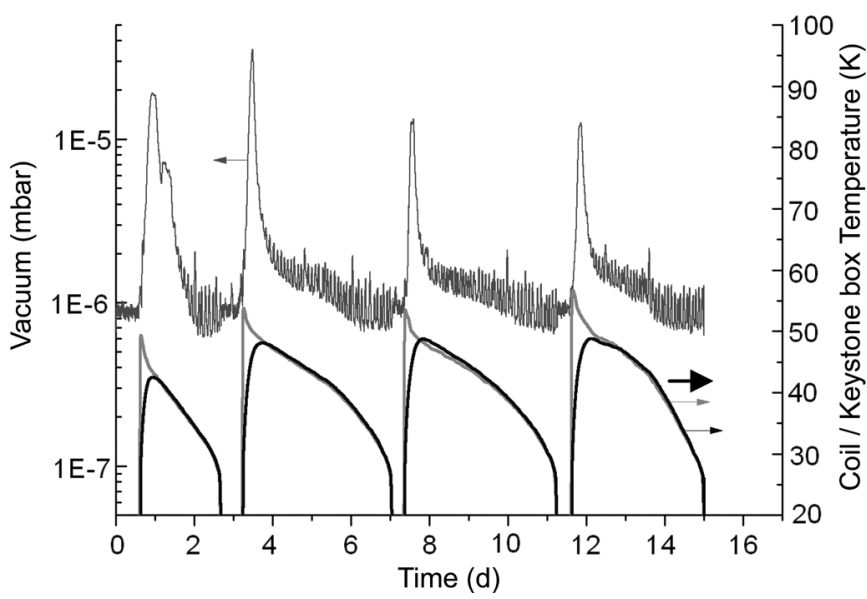

Fig. 4. The whole surface of the cold mass works like a cryogenic pump. Cryopumping dominates at liquid helium temperature but after a fast discharge gases are released and pressure rises. Warm-up of the keystone structure takes some hours and this allows the vacuum to be kept at a safe level.

\section{TEST}

\section{A. Vacuum}

The internal volume of an ECT of about $350 \mathrm{~m}^{3}$ is first pumped by a rotary pump down to the mbar level within one day. Then a set rotary piston pumps is used to bring it down to $10^{-1}$ mbar in a half day. To shorten the time of pumping a temporary turbo molecular pump was installed at the top of the services support structure. It helped to quickly bring down the vacuum level and enable switching to the diffusion pumps (at $2 * 10^{-3}$ mbar). The diffusion pumps bring down the vacuum level to $\sim 10^{-4}$ mbar after which cooling is started.

The current vacuum level at normal operation is about $10^{-7}$ mbar. During the assembly phase of the ATLAS detector the Barrel Toroid and ECT vessels where isolated during the day time by closing the gate valves. An estimation of the effective gas load of the ECT gives a value of $10^{-3} \mathrm{mbar} \cdot 1 / \mathrm{s}$. This is a combination of out-gassing and diffusion through O-rings.

At lower temperature an important fraction of the pumping capacity comes from cryopumping. Fig. 4 shows the vacuum behavior after fast discharges of the magnet. The graphs shows the desorption of the molecules from the coil casings as they heat up as a result of the fast discharge. The cryopumping of the cold mass is both an advantage and a liability. If diffusion comes to dominate the leak rate the accumulated molecules at the cold mass could give rise to an unwanted vacuum degradation. To determine this influence is part of ongoing work. To enable the reduction of the influence of diffusion through the O-rings the ECT's have a double O-ring sealing with an external connection to the inter sealing space. If required these spaces can be pumped to roughing level, which would give a significant reduction in the influence of the permeation of gases through the 120-meter long vacuum seal.

\section{B. Cool Down}

The ECTs where tested in two campaigns defined by restrictions from the ATLAS detector. The magnets where cooled for the first campaign in December 2007. The cool down behavior 


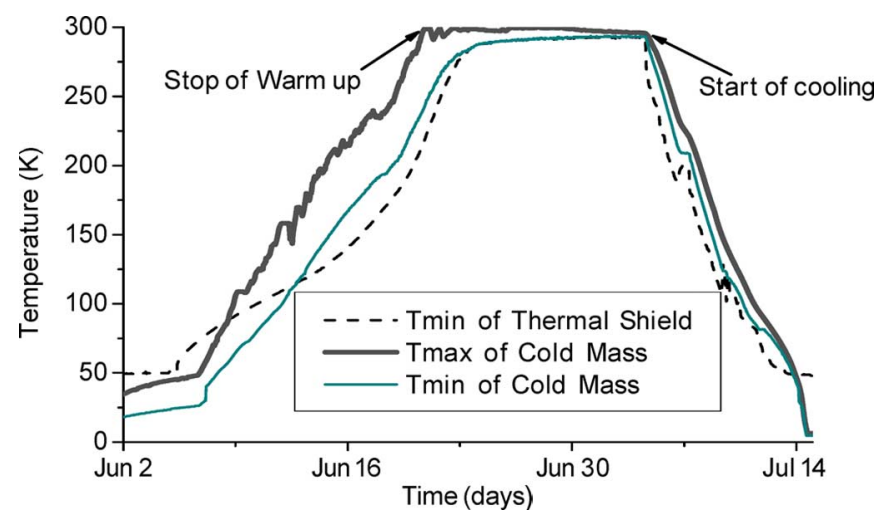

Fig. 5. ECT A was warmed up for an intervention in the He circuit. Therefore the warm up is done using the ohmic resistance of the coils. The cool down and warm up are driven by the allowable thermal gradients in the cold mass.

was determined by the maximum allowed thermal gradient in the mechanical structure of the cold mass. The cold mass is an assembly of the eight coils with spacer elements between. The main connections are shimmed with epoxy and aluminum and bolted. A maximum gradient of $30 \mathrm{~K}$ was allowed between the sensors. This implies that the gradient in the connections are far smaller. Before the second test campaign the temperature in the ECTs was varied between $4 \mathrm{~K}$ and $70 \mathrm{~K}$ to measure the thermal behavior, this is be presented in a separate paper [5]. After the testing of ECTC, ECTA developed a leak in the electrical insulator of the cooling circuit of the current leads.

The leak, although acceptable at first, opened up as a result of the thermal cycles which are inherent to the operation of the magnet system. Given the position of ECTA inside the detector and all the electronics inside the detector, condensation on the vessel is not acceptable. Therefore, ECTA was warmed up using the ohmic resistance of the coils. To effectuate the repair a man hole was cut in the turret to allow access at the insulators.

The insulators which were effectively pipe connections separated by an epoxy layer, were replaced by ceramic insulators. As ceramics are less resistant to tension forces, the connection was modified such that tension forces were minimized. Following the repair, ECTA was cooled down again. The warm up and cool down is presented in Fig. 5. Given the operational capacity of the ATLAS cooling plant the shields could not be warmed up by forced flow. The shields, (20 tons), where warmed up using the radiative heating from the coils.

\section{Testing}

The tests were performed to verify the behavior of the control and safety system, to verify the temperature rise of the coils/ cold mass at fast discharge, to verify the current lead cooling behavior and to verify the mechanical behavior of the system. The verification of the mechanical behavior is very limited as the loads will be completely different when the ECT's are operated in the field of the Barrel Toroid.

The magnet safety system MSS has two main functions; first is to protect the magnet itself, this is basically two identical passive systems, which, based on information from voltage bridges and Superconducting Quench Detector can initiate a fast discharge. Secondly, an active control system monitors services

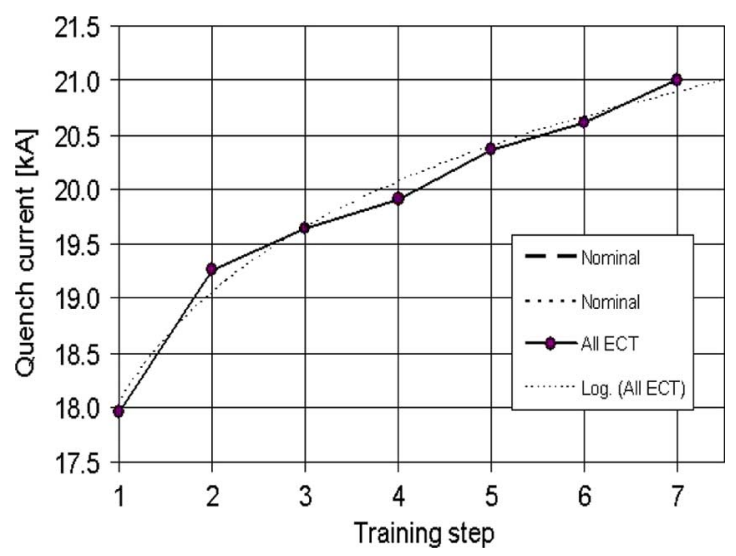

Fig. 6. Training steps. The operational current of toroids was only attained after training. The graph shows the training steps of both magnets. The training was continued to $21 \mathrm{kA}$ to give a better match to the mechanical loads during the combined operation of the Barrel Toroid and the two ECTs. All training quenches have been in different coils. There is no conclusive information on what causes of the quenches.

for the magnet and can initiate a slow discharge in the case of failure of the services of the magnet system. The voltage bridges get their information from voltage taps, which are connected to each double pancake and all interconnections. The magnet control system (MCS) provides the information from the instrumentation and provides the interface with cryogenics, vacuum and other services. An important aspect of MCS is the control of the current leads cooling. Tests at low current, $(3 \mathrm{kA})$, showed the reliability of the control and safety system.

Following this initial test both ECTs where powered to 7.5 and $10 \mathrm{kA}$. The tests at $10 \mathrm{kA}$ showed a significant non-uniformity in the quench behavior of the coils. This provoked a study on the quench propagation as function of the current and the effect of non-uniform heat distribution in the cold mass. The results of this study are presented separately [6]. The study shows the importance of the distance between the heaters and the coil packages. For production reasons the heaters where mounted on the outside of the coil casing on the tails of the superconductor. This leads to a relative large distance between the heater and the coil package. Given this length of superconductor, the cooling effect on this section at lower energy density and the difference in RRR values in different coils becomes an important effect in terms of the quench propagation. Later tests at higher current confirmed this. The delay between the quenching of the different coils ranges from $\sim 120 \mathrm{~s}$ at $10 \mathrm{kA}$ to $4 \mathrm{~s}$ at $20.5 \mathrm{kA}$.

The ECTs were tested to $21 \mathrm{kA}$ and training was observed in both of them. Although the design current was $20 \mathrm{kA}$ training was made up to $21 \mathrm{kA}$ to give a better match to the mechanical loads during the combined operation of the Barrel Toroid and the two ECTs as the nominal current was set to be $20.5 \mathrm{kA}$. The training quenches are depicted in Fig. 6.

Given the available instrumentation the possibilities for localizing the quench are limited. For a coil the localization is limited to the double pancake level. Given this limitation it is not clear what caused the quenches. As the interconnections are monitored separately and it was confirmed they were not the cause of a quench, the cause of the quenches is most likely related to the fabrication of the coils. 


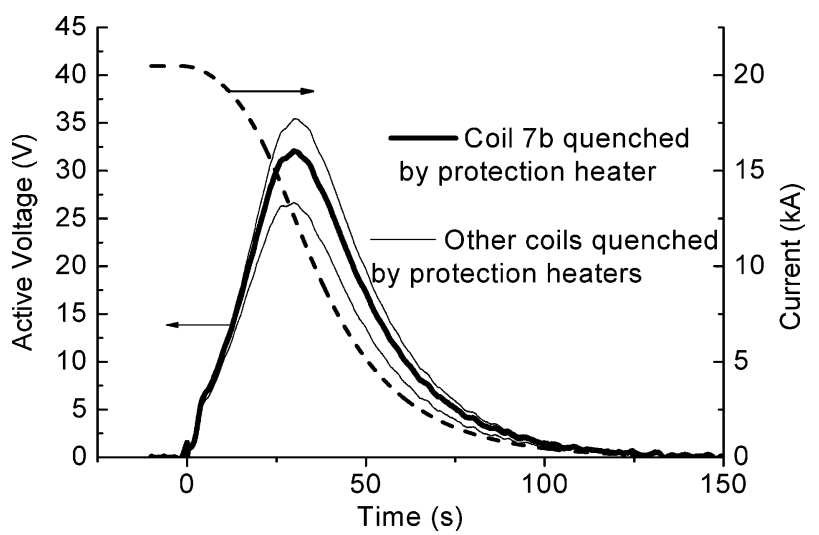

Fig. 7. The only way to reduce the magnetic field in a short time is to initiate multiple normal zones in the coils by using so called quench heaters. In a few seconds after a fast discharge command (at time " 0 " in the left figure) the normal zone reaches the coils and stored energy starts to warm up the entire magnet in a homogenous way.

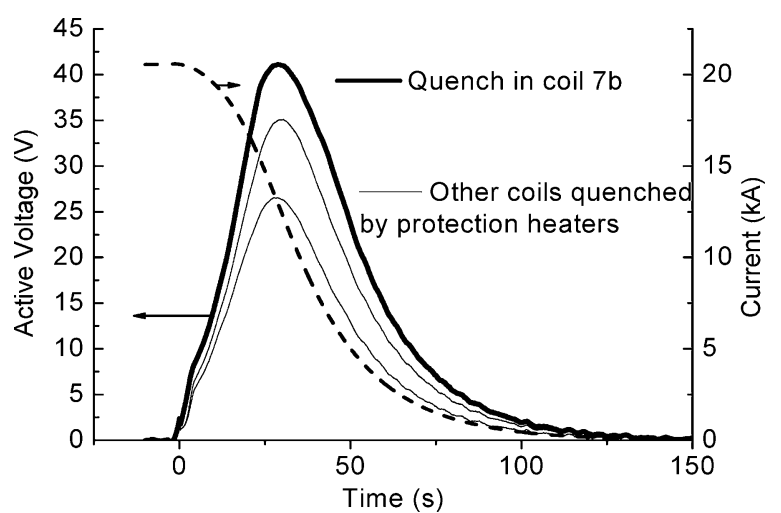

Fig. 8. One of the training quenches happened (at time " 0 " in the right figure) at $20.6 \mathrm{kA}$ (20.5 kA is operating current). More energy is dissipated in one of the double pancakes and its active voltage is higher. Other coils behave identically as during the fast discharge process. In both cases the active voltages stay below some $40 \mathrm{~V}$.

\section{POWERING AND DISCHARGE}

The ECT's where powered using the power supply in current control mode at a level of $3 \mathrm{~A} / \mathrm{s}$ to full current. The coils show an increase of temperature during ramping, though this heat is dissipated in a few minutes after the ramp is stopped. As the ramp rate for powering the full magnet system will be below $2 \mathrm{~A} / \mathrm{s}$ this heating is considered well within the margins of the system. For the slow discharge the energy in the magnets is dissipated in a set of externally connected resistors, resulting in a current decay rate of $7 \mathrm{~A} / \mathrm{s}$ at high current falling down to $2 \mathrm{~A} / \mathrm{s}$ at low current.

In fast discharge mode the energy is dumped in the conductor and diffuses to the aluminum structure of the cold mass. The maximum current decay rate is about $500 \mathrm{~A} / \mathrm{s}$. This results in a maximum active voltage in a double pancake of maximum $36 \mathrm{~V}$ (Fig. 7) for normal fast dump and $45 \mathrm{~V}$ in the case of a coil quench (Fig. 8). The graph also shows that the initiation of the normal zone is not dependant on the behavior of neighboring coils.

\section{RESULTS AND OUTLOOK}

The stand alone operation of both ECTs has been proven, after four training quenches of ECTA and three training quenches in ECTC. The attained current of $21 \mathrm{kA}$ is $2.5 \%$ above nominal current and 5\% above design current. The occurrence of training was not expected as the intent of the design was to give the system far larger margins. For the moment, the reduced margin could not be attributed to specific causes.

The functioning of the control and safety system has been proven. Fast discharge has shown consistent behavior of coils in both initiation of the fast discharge and the dissipated energy per coil. The maximum temperature rise after fast discharge is about $60 \mathrm{~K}$, well within the design limits. The fast discharge causes a significant degradation of the vacuum level, though remains within operational requirements.

The test of the single ECT showed that the magnets are ready for the next step, which is the combined test of all toroids together, the Barrel Toroid and the two End Cap Toroids. The emphasis will then be more on the mechanical structure as the combined operation of Barrel Toroid and ECT will induce a Lorentz force load of 240 tons on the structure in axial direction at either side.

\section{ACKNOWLEDGMENT}

The authors wish to acknowledge many contributions to the project which have enabled the progress of the last year. The ATLAS team has received essential support from the various CERN groups for cryogenics, controls and transport services.

\section{REFERENCES}

[1] H. H. J. ten Kate, "ATLAS superconducting magnet system completion," IEEE Trans. Appl. Supercond., vol. 19, no. 3, Jun. 2009.

[2] H. H. J. ten Kate, "The ATLAS superconducting magnet system: Status of construction and installation," IEEE Trans. Appl. Supercond., vol. 16, p. 499, 2006.

[3] D. E. Baynham, F. S. Carr, E. Holtom, J. Buskop, A. Dudarev, G. Vandoni, R. Ruber, A. Foussat, M. Losasso, P. Benoit, R. Pengo, L. Stewart, A. Olyunin, V. Stepanov, N. Kopeykin, I. Shugaev, M. Arnaud, and H. H. J. ten Kate, "ATLAS end cap toroid final integration, test and installation," IEEE Trans. Appl. Supercond., vol. 18, pp. 391-394, 2008.

[4] D. E. Baynham, F. S. Carr, E. Holtom, E. F. Towndrow, H. H. J. ten Kate, A. Dudarev, and J. Buskop, "ATLAS end cap toroid cold mass and cryostat integration," IEEE Trans. Appl. Supercond., vol. 16, pp. 537-540, 2006.

[5] G. Passardi, K. Barth, N. Delruelle, A. Dudarev, F. Haug, O. Pavlov, M. Pezzetti, O. Pirotte, H. H. J. Ten Kate, D. E. Baynham, C. Mayri, R. Pengo, and A. Yamamoto, "First cool-down and test at $4.5 \mathrm{~K}$ of the ATLAS superconducting magnet system assembled in the LHC experimental cavern," in ICEC 22-ICMC 2008, to be published.

[6] G. Volpini, G. Baccaglioni, D. E. Baynham, C. Berriaud, A. Dudarev, and H. H. J. ten Kate, "Effects of unequal inter and intra-toroid response times on the quench performance of the system of three ATLAS toroids," IEEE Trans. Appl. Supercond., vol. 19, no. 3, Jun. 2009. 